\title{
Twin Anemia Polycythemia Sequence: Current Views on Pathogenesis, Diagnostic Criteria, Perinatal Management, and Outcome
}

\author{
Lisanne S. A. Tollenaar, ${ }^{1}$ Femke Slaghekke, ${ }^{1}$ Johanna M. Middeldorp, ${ }^{1}$ Frans J. Klumper, ${ }^{1}$ \\ Monique C. Haak, ${ }^{1}$ Dick Oepkes, ${ }^{1}$ and Enrico Lopriore ${ }^{2}$ \\ ${ }^{1}$ Division of Fetal Medicine, Department of Obstetrics, Leiden University Medical Centre, Leiden, the Netherlands \\ ${ }^{2}$ Division of Neonatology, Department of Pediatrics, Leiden University Medical Centre, Leiden, the Netherlands
}

\begin{abstract}
Monochorionic twins share a single placenta and are connected with each other through vascular anastomoses. Unbalanced inter-twin blood transfusion may lead to various complications, including twin-to-twin transfusion syndrome (TTTS) and twin anemia polycythemia sequence (TAPS). TAPS was first described less than a decade ago, and the pathogenesis of TAPS results from slow blood transfusion from donor to recipient through a few minuscule vascular anastomoses. This gradually leads to anemia in the donor and polycythemia in the recipient, in the absence of twin oligo-polyhydramnios sequence (TOPS). TAPS may occur spontaneously in 3-5\% of monochorionic twins or after laser surgery for TTTS. The prevalence of post-laser TAPS varies from $2 \%$ to $16 \%$ of TTTS cases, depending on the rate of residual anastomoses. Pre-natal diagnosis of TAPS is currently based on discordant measurements of the middle cerebral artery peak systolic velocity (MCA-PSV; $>1.5$ multiples of the median $[\mathrm{MoM}]$ in donors and $<1.0$ in recipients). Post-natal diagnosis is based on large inter-twin hemoglobin $(\mathrm{Hb})$ difference $(>8 \mathrm{~g} / \mathrm{dL})$, and at least one of the following: reticulocyte count ratio $>1.7$ or minuscule placental anastomoses. Management includes expectant management, and intra-uterine blood transfusion (IUT) with or without partial exchange transfusion (PET) or fetoscopic laser surgery. Post-laser TAPS can be prevented by using the Solomon laser surgery technique. Short-term neonatal outcome ranges from isolated inter-twin $\mathrm{Hb}$ differences to severe neonatal morbidity and neonatal death. Long-term neonatal outcome in post-laser TAPS is comparable with long-term outcome after treated TTTS. This review summarizes the current knowledge after 10 years of research on the pathogenesis, diagnosis, management, and outcome in TAPS.
\end{abstract}

Keywords: monochorionic twins, twin anemia polycythemia sequence, anemia, polycythemia

Monochorionic twin pregnancies are at increased risk for adverse outcome compared to dichorionic twin pregnancies and singletons. This is primarily due to the fact that almost all monochorionic twins share a single placenta, with inter-twin anastomoses allowing blood to flow bidirectionally between the two fetuses. Unbalanced net intertwin blood transfusion may lead to various complications, including TTTS and twin anemia polycythemia sequence (TAPS). TTTS was first described in the 19th century and results from imbalanced inter-twin blood flow causing hypovolemia and oligohydramnios in the donor and hypervolemia and polyhydramnios in the recipient twin, the socalled TOPS. TAPS is a newly described form of chronic and slow inter-twin blood transfusion characterized by large inter-twin $\mathrm{Hb}$ differences without signs of TOPS. The pathogenesis of TAPS is based on the presence of a few minuscule vascular anastomoses. TAPS may occur sponta- neously in monochorionic twin pregnancies or may occur in TTTS cases after incomplete laser surgery due to a few small residual anastomoses. The post-laser form of TAPS was first described in 2006 (Robyr et al., 2006), whereas the spontaneous form of TAPS, as well as the acronym TAPS, was first described in 2007 (Lopriore, Middeldorp et al., 2007). In the past decade, over 100 studies have been published on TAPS, and our knowledge and awareness have gradually increased. This review focuses on the epidemiology, pathogenesis, diagnostic criteria, management op-

RECEIVED 19 January 2016; ACCEPTED 1 February 2016. First published online 12 April 2016.

ADDRESS FOR CORRESPONDENCE: E. Lopriore, Department of Pediatrics, Leiden University Medical Center, J6-S, Albinusdreef 2, 2333 ZA Leiden, the Netherlands. E-mail: e.lopriore@lumc.nl 


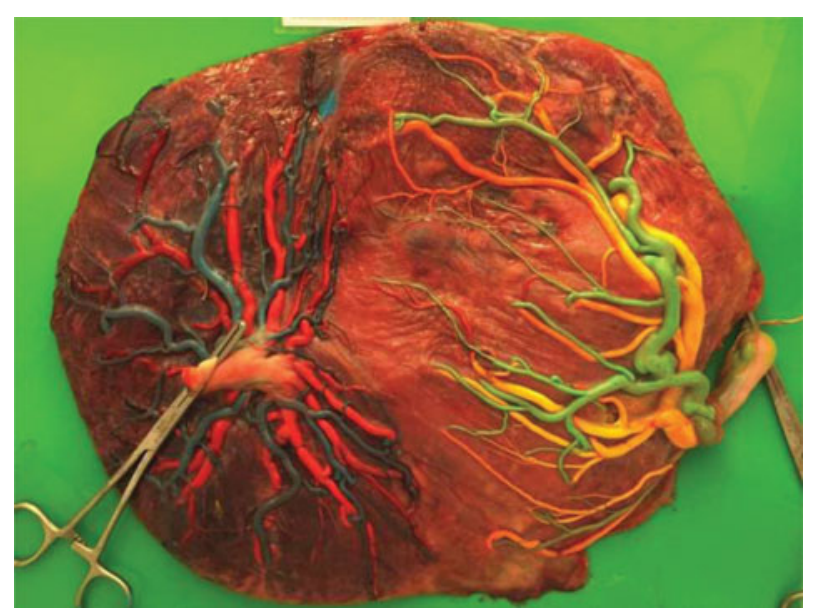

\section{FIGURE 1}

(Colour online) A spontaneous TAPS placenta injected with color dye. Blue and green dye was used for the arteries and yellow and pink for the veins, showing the presence of only a few very small anastomoses.

tions, and short- and long-term outcome in TAPS, and summarizes the data gathered since the first description of TAPS a decade ago.

\section{Epidemiology}

TAPS may occur spontaneously (spontaneous TAPS) or after laser treatment for TTTS (post-laser TAPS). Spontaneous TAPS occurs in 3-5\% of monochorionic twin pregnancies (Casanova et al., 2014; Gucciardo et al., 2010; Lewi et al., 2008; Lopriore et al., 2009; Yokouchi et al., 2015), whereas post-laser TAPS occurs in $2-16 \%$ of TTTS cases after incomplete laser treatment (Habli et al., 2009; Robyr et al., 2006; Slaghekke, Lewi et al., 2014). The wide range in incidence rate in post-laser TAPS can be explained by the use of different laser surgical techniques and/or the existence of different definitions and criteria for TAPS (see sections below).

\section{Pathogenesis}

\section{Placental Characteristics}

The pathogenesis of TAPS is based on the unique angioarchitecture of the placenta, characterized by the presence of only few minuscule anastomoses. These few small anastomoses shared between the two placentas allow a chronic and slow transfusion of blood from the donor to the recipient twin (Figure 1). The actual blood flow through these small anastomoses ranges from 5 to $15 \mathrm{~mL}$ per 24 hours (Lopriore, Middeldorp et al., 2007; Lopriore, van den Wijngaard et al., 2007). This process gradually leads to highly discordant $\mathrm{Hb}$ levels, causing the donor twin to become anemic and the recipient twin to become polycythemic. In monochorionic placentas, three types of anastomoses have been described: arterio-venous (AV), arterio-arterial (AA), and veno-venous (VV) anastomoses. AV anastomoses are unidirectional whereas AA and VV anastomoses are bidirectional. TAPS placentas are characterized by the presence of a few very small AV anastomoses, with a diameter $<1$ $\mathrm{mm}$. TAPS placentas have on average 3 to 4 anastomoses compared to an average of 8 anastomoses in normal monochorionic placentas (Zhao et al., 2013). AA anastomoses are rare in TAPS cases and occur in 10-20\% of TAPS placentas. AA anastomoses are considered to protect against the development of TTTS or TAPS because of the bidirectional blood flow, allowing inter-twin equilibration of blood volumes (de Villiers et al., 2012; Lopriore, van den Wijngaard et al., 2007; Suzuki, 2010; van Meir et al., 2010).The size of AA-anastomoses in TAPS appear to be significantly smaller (diameter $<1 \mathrm{~mm}$ ) compared to AA anastomoses in TTTS cases or in uncomplicated monochorionic twins (Zhao et al., 2013). Spontaneous TAPS placentas differ from post-laser TAPS placentas. Spontaneous TAPS placentas have a higher total number of anastomoses compared to post-laser TAPS placentas, 4 versus 2, respectively. Miniscule AA anastomoses were detected sporadically in both groups, but the rate of AA anastomoses was slightly higher in the spontaneous group (de Villiers et al., 2013).

\section{TAPS Versus TTTS}

The absence of oligohydramnios and polyhydramnios is an essential element in the diagnosis of TAPS. The presence of TOPS is only pathognomonic for TTTS. Importantly, $2-8 \%$ of TTTS cases may have pre-operative signs of severe fetal anemia in the donor and polycythemia in the recipient (Donepudi et al., 2015; Van Winden et al., 2015)

The mechanism preventing the donor twin to develop oligohydramnios and the recipient twin to develop polyhydramnios in TAPS cases is not entirely clear. The most probable explanation is that due to the chronic character of TAPS, slow inter-twin blood transfusion allows more time for the hemodynamic compensatory mechanisms to take place (Lopriore, Deprest et al., 2008). While TTTS results from large, unbalanced inter-twin blood transfusion in combination with unbalanced hormonal regulation with rapid deterioration, TAPS probably results from slow inter-twin blood transfusion without hormonal imbalance and a slow deterioration (van den Wijngaard et al., 2007). In TTTS, donor twins show high renin levels, presumably as a result of renal hypoperfusion (Mahieu-Caputo et al., 2000), and recipients have absent renin protein, presumably because of down-regulation due to hypervolemia. This hormonal discordance has not been described in TAPS pregnancies.

Interestingly, in post-laser TAPS, it is usually the former recipient who becomes anemic, whereas the former donor becomes polycythemic (Lewi et al., 2006; Robyr et al., 2005, 2006; Yamamoto et al., 2005). A possible explanation could be that the colloid osmotic pressure of the ex-recipient is 
strongly increased prior to and shortly after laser therapy, which attracts excess fluid from the maternal blood to the recipient's fetal blood. This source of increased fetal plasma volume followed by amniotic fluid production may delay the development of oligohydramnios in the ex-recipient who becomes the TAPS donor (van den Wijngaard et al. 2007).

\section{TAPS Versus Uncomplicated Monochorionic Twins}

In addition to the small anastomoses that characterize TAPS placentas, TAPS placentas also show a remarkable difference in placental shares. In uncomplicated monochorionic twins, the placental share is the principal element affecting fetal growth and final birth weight, that is, the smaller twin usually has a relatively smaller placental share (Lewi et al., 2007). In TAPS twins, the donor twin is usually smaller than the recipient twin but often has a paradoxically larger placental share compared to its co-twin. In contrast to uncomplicated monochorionic twins, fetal growth in TAPS appears to be primarily determined by inter-twin blood transfusion rather than placental share. A relatively larger placental share may enable the fetal survival of the anemic twin in TAPS (Zhao et al. 2014). In addition, TAPS donor twins also have hypoalbuminemia and hypoproteinemia due to loss of not only blood cells, but also proteins and nutrients, which may partly also affect their fetal growth (Verbeek et al., 2013).

\section{Diagnosis}

TAPS can be diagnosed either antenatally or post-natally. TAPS is characterized by Hb differences with the absence of antenatal ultrasound signs of polyhydramnios in the recipient and oligohydramnios in the donor. Antenatal diagnosis is based on ultrasound abnormalities whereas the post-natal diagnosis is derived from large inter-twin hematologic discordances and characteristic placental angioarchitecture.

\section{Antenatal Criteria}

Antenatal diagnosis of TAPS is based on Doppler ultrasound abnormalities. MCA-PSV measurement, a non-invasive test, has become the standard test for the prediction of fetal anemia in singletons in a variety of fetal diseases. In TAPS, this test will show an increased MCA-PSV in the donor twin, suggestive of fetal anemia, and decreased velocities in the MCA-PSV in the recipient, suggestive of polycythemia. During the past decade, different MCA-PSV values for the diagnosis of TAPS have been proposed. Robyr et al. (2006) initially suggested the use of a MCA-PSV $>1.5 \mathrm{MoM}$ for the donor twin and $<0.8 \mathrm{MoM}$ for the recipient twin. However, Slaghekke et al. (2010) showed that a MCA-PSV between 0.8 and 1.0 MoM in the recipient was also frequently found in post-natally diagnosed TAPS cases and suggested therefore the currently used cut-off of MCA-PSV $<1.0 \mathrm{MoM}$ in the recipient twin and $>1.5 \mathrm{MoM}$ in the donor twin. This cutoff level is characterized by high sensitivity and specificity of MCA-PSV for both anemia and polycythemia, confirming the clinical usefulness of this non-invasive test (Slaghekke et al., 2010). The MCA-PSV measurement has a high diagnostic accuracy for predicting abnormal $\mathrm{Hb}$ levels in fetuses with TAPS (Slaghekke, Pasman et al., 2015; Veujoz et al. 2015). However, the high predictive value of MCAPSV measurements reported in the study from Slaghekke et al. (2010) was determined in a highly selected group of TAPS-only cases followed in a specialized fetal therapy center. In a recent study, Fishel-Bartal et al. (2015) did not find a similar predictive value of MCA-PSV for the detection of polycythemia in monochorionic twins. MCA-PSV measurement in polycythemic twins did not differ compared to normal twins. Fishel-Bartal et al. (2015) did find a significant correlation between a large inter-twin difference in MCA-PSV (delta MCA-PSV) and large inter-twin hematocrit difference and proposed the alternative use of a delta MCA-PSV $>0.5$ MoM instead of the currently used fixed cut-off levels of $<1.0 \mathrm{MoM}$ and $>1.5 \mathrm{MoM}$ for the pre-natal diagnosis of TAPS.

In some TAPS cases, additional ultrasound findings have been reported. In several cases of spontaneous TAPS, a striking difference in placental thickness and echodensity on ultrasound examination was detected (Figure 2; Movva \& Rijhsinghani, 2014; Slaghekke et al., 2010; Stritzke et al., 2014). This difference can be explained by the hydropic and echogenic character of the anemic placental share in contrast to the normal appearance of the polycythemic placental share. Another ultrasound finding described in TAPS is the so-called 'starry sky liver' (Figure 3; Soundararajan \& Howe, 2014). Starry sky appearance refers to a sonographic pattern of the liver, characterized by clearly identified portal venules (stars) and diminished parenchymal echogenicity (sky) that accentuates the portal venule walls. Starry sky liver is usually reported in acute hepatitis, but other conditions like heart failure can lead to this typical finding as well. More studies are needed to further investigate the validity and significance of these antenatal ultrasound findings for the diagnosis of TAPS.

Since diagnosis of TAPS at an earlier gestational age is associated with more favorable outcomes (Rossi \& Prefumo, 2014), we recommend the routine use (at least biweekly) of MCA-PSV Doppler ultrasound measurements in all monochorionic pregnancies to timely detect TAPS.

\section{Postnatal Criteria}

In $40-63 \%$ of the cases, TAPS is not detected antenatally, but is only diagnosed after birth (de Villiers et al., 2013; Slaghekke et al., 2010). Therefore, post-natal diagnostic criteria have been proposed. These criteria are based on the presence of (chronic) anemia in the donor and polycythemia in the recipient twin (Figure 4) and the characteristic angioarchitecture of the placenta. Different cut-off 


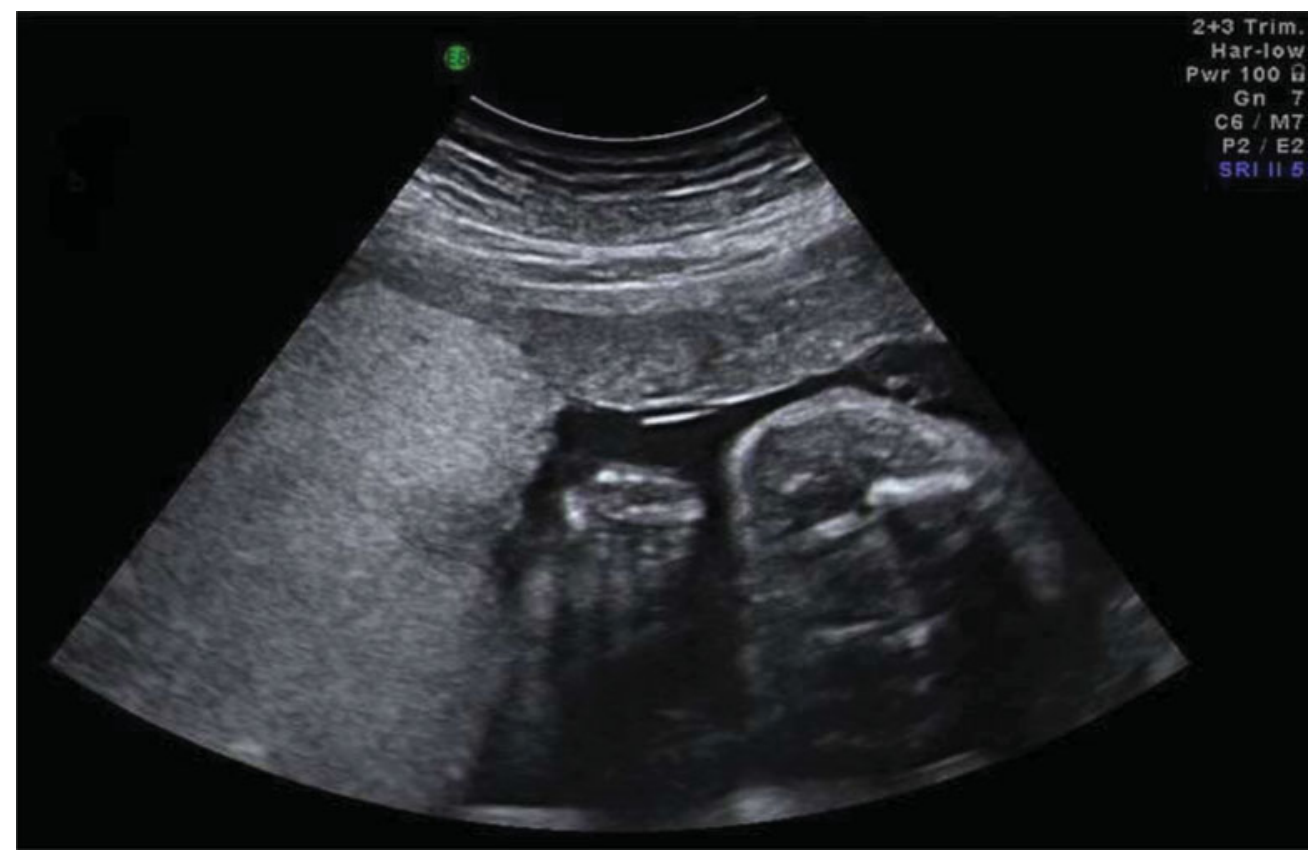

\section{FIGURE 2}

(Colour online) Ultrasound image of a TAPS placenta showing a difference in placental thickness and echodensity. On the left side of the image the hydropic and echogenic placental share of the anemic donor and on the right side the normal aspect of the placenta of the recipient is depicted.

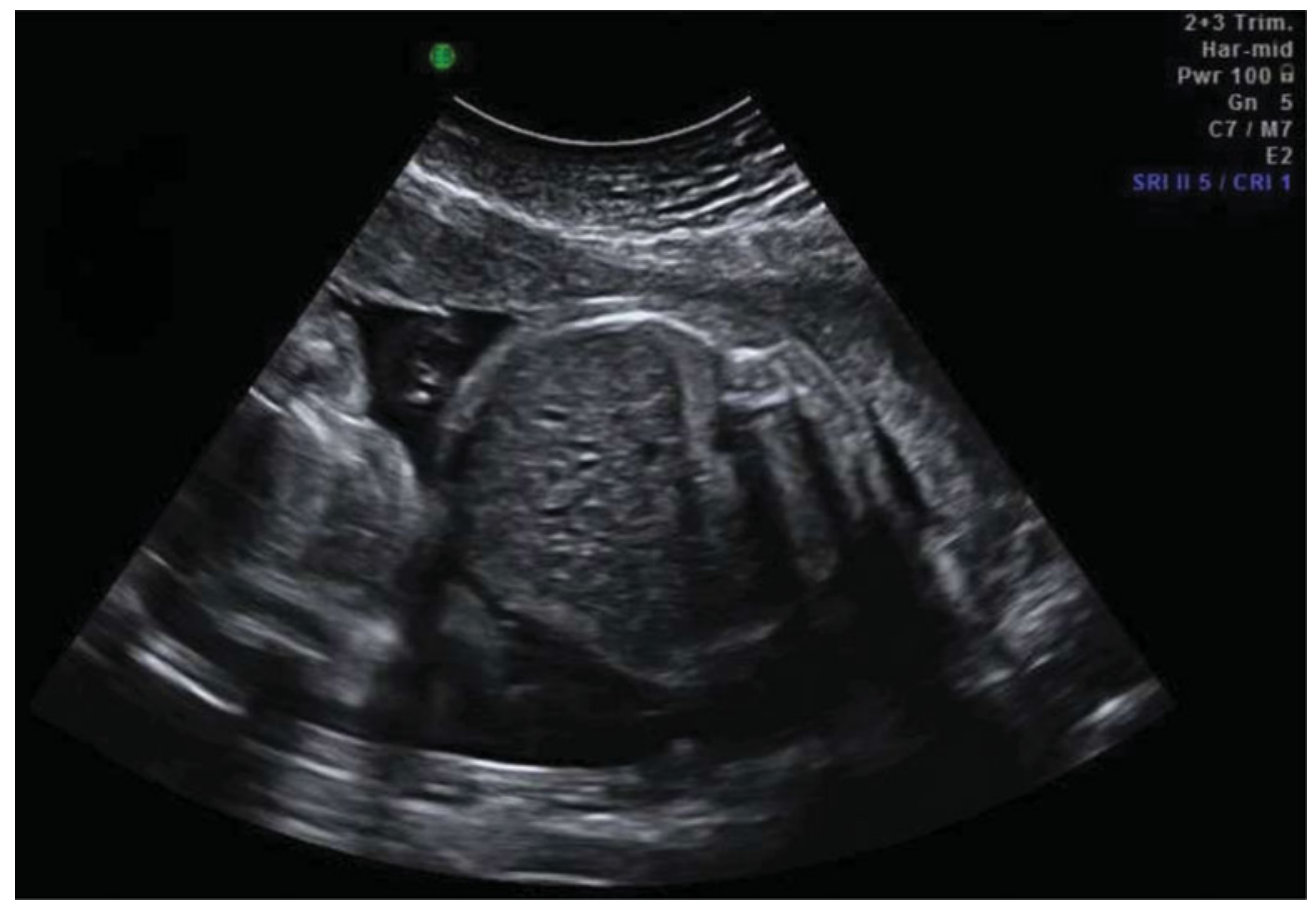

\section{FIGURE 3}

(Colour online) Ultrasound image showing a starry sky liver in a TAPS recipient with clearly identified portal venules (stars) and diminished parenchymal echogenicity (sky) that accentuates the portal venule walls. 


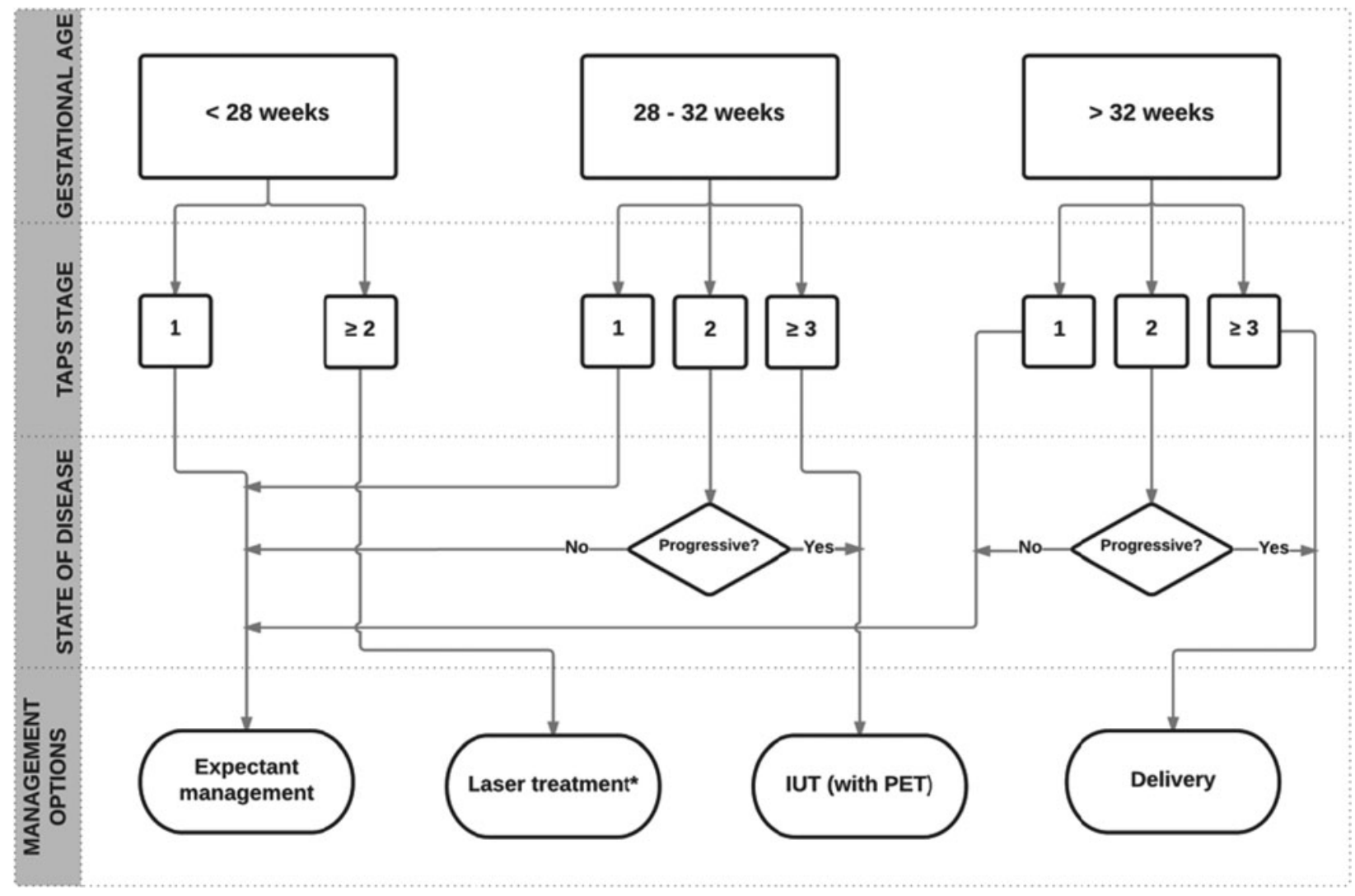

FIGURE 4

Flowchart with antenatal management options for TAPS.

levels for anemia and polycythemia have been used since the first description of TAPS in the last decade. Lewi et al. (2008) first defined TAPS as the presence of an Hb level $<11 \mathrm{~g} / \mathrm{dL}$ in the anemic twin and $>20 \mathrm{~g} / \mathrm{dL}$ in the polycythemic co-twin. However, absolute $\mathrm{Hb}$ levels do not take the positive association between $\mathrm{Hb}$ levels and higher gestational age into account. Fetal $\mathrm{Hb}$ concentrations are known to increase linearly with gestation (Jopling et al., 2009; Lubin, 1978; Nicolaides et al., 1989). Lopriore, Middeldorp et al. (2007) used gestational-age-dependent cut-off levels to define anemia in the donor $(\mathrm{Hb}<5$ th centile) and polycythemia in the recipient (hematocrit $>65 \%$ ). However, this contained practical disadvantages since it required the use of specific normograms related to gestational age. Several normograms have been published and differ slightly from one another (Jopling et al., 2009; Nicolaides et al., 1989). Since a fixed inter-twin $\mathrm{Hb}$ difference is a more logical and pragmatic criterion, nowadays an inter-twin $\mathrm{Hb}$ difference $>8 \mathrm{~g} / \mathrm{dL}$ is commonly used, based on a case-control study were all TAPS cases had an inter-twin $\mathrm{Hb}$ difference $>8$ $\mathrm{g} / \mathrm{dL}$ (Lopriore et al., 2010).

A large $\mathrm{Hb}$ difference $(>8 \mathrm{~g} / \mathrm{dL})$ at birth is also detected in case of acute peripartum TTTS. Distinction between these two clinical pictures (TAPS and acute peripartum TTTS) is important, as they require a different therapeu- tic neonatal management. Two additional criteria are required to distinguish TAPS from acute peripartum TTTS (Lopriore et al., 2005). The first criterion is an increased reticulocyte count measured in the TAPS donor (as a result of increased erythropoiesis due to chronic anemia). An inter-twin reticulocyt count ratio $>1.7$ is pathognomonic for TAPS (Lopriore et al., 2010). This ratio is measured by dividing the reticulocyte count of the donor by the reticulocyte count of the recipient. The second criterion for the post-natal diagnosis of TAPS is the presence of small residual anastomoses (diameter $<1 \mathrm{~mm}$ ) at the placental surface (Slaghekke et al., 2010), detected through color dye injection of the placenta (Lopriore et al., 2011). In acute peripartum TTTS, blood transfusion from the donor twin to the recipients occurs rapidly and reticulocyte count in the donor is typically still low. Acute anemia will eventually lead to increased erythropoiesis, but the increased reticulocyte production is not detected in the acute phase. In addition, in contrast to TAPS, the pathogenesis of acute peripartum TTTS is based on large placental AA or VV anastomoses with low resistance, allowing large amount of blood to flow directly from the donor to the recipient (Lopriore et al., 2005).

Since reticulocyte count is not always measured and placental injection is difficult to perform, we recently studied a 


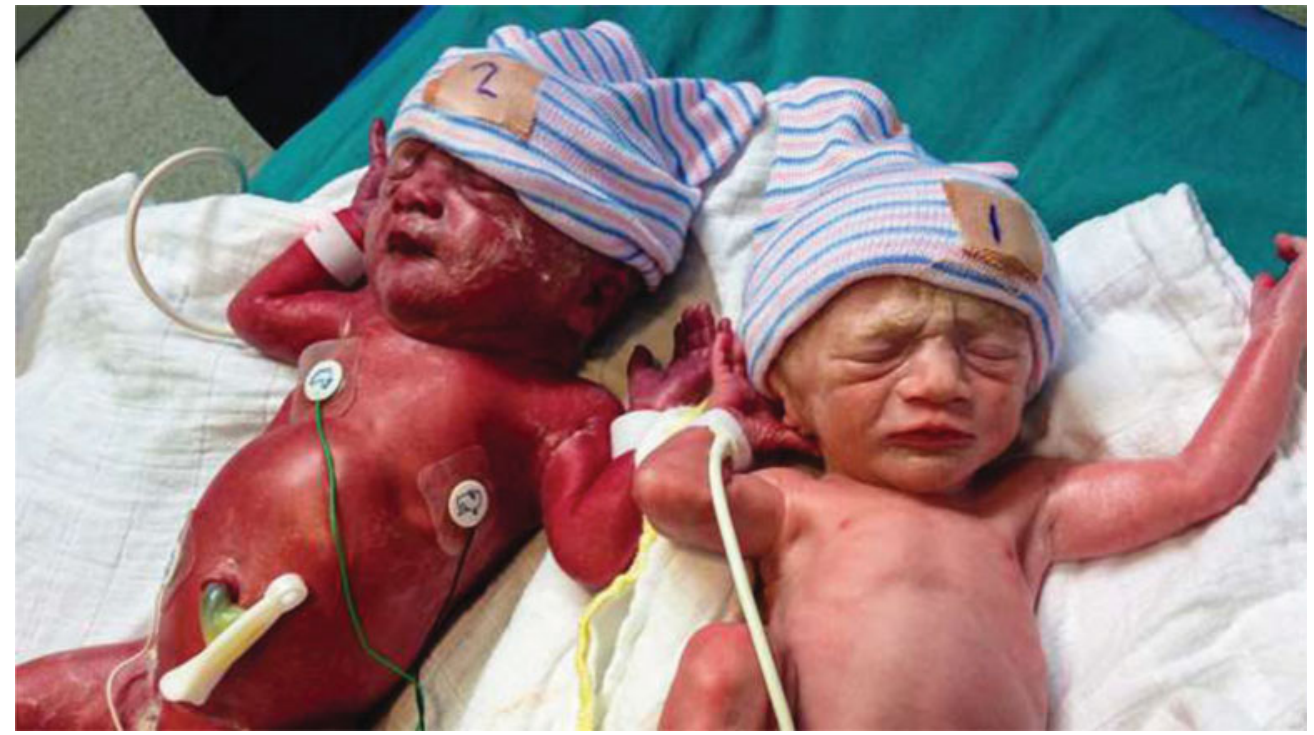

\section{FIGURE 5}

(Colour online) Spontaneous TAPS twins at birth. On the left, the plethoric polycythemic recipient and on the right the pale anemic donor.

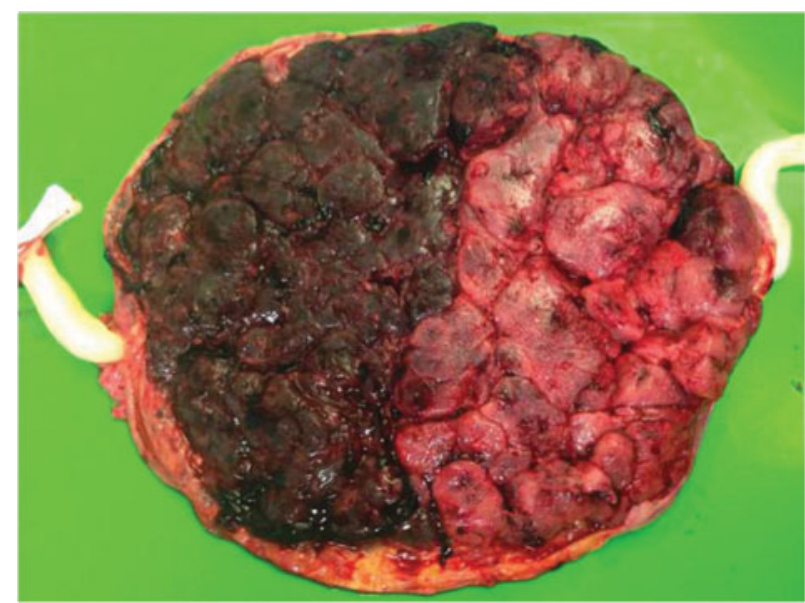

\section{FIGURE 6}

(Colour online) Maternal side of the TAPS placenta showing the difference in color between the plethoric share of the recipient (left side of the placenta) and the anemic share of the donor (right side of the placenta).

new additional criterion for post-natal diagnosis of TAPS. In analogy with the difference in skin color of the TAPS twins at birth (the anemic donor is pale and the polycythemic recipient is plethoric), the maternal side of the TAPS placenta also shows a striking color difference (Figure 5 \& Figure 6). We developed a new quick and easy tool to determine the color difference ratio (CDR) between the two placental shares using digital pictures (Tollenaar et al., 2016). We found that TAPS placentas had a significantly higher CDR $(>1.5)$ compared to uncomplicated monochorionic twin placentas. Whether this method can eventually be added to the list of post-natal criteria requires further investigations in larger series of placentas with and without TAPS to determine the sensitivity and specificity of the test. Importantly, CDR measurements should also be investigated in placentas with acute TTTS to determine whether this method can help distinguish TAPS cases from cases with acute peripartum TTTS, since in both situations large inter-twin $\mathrm{Hb}$ differences are present at birth.

\section{Classification}

Since TAPS is a heterogeneous disease, a staging system can be helpful to discriminate between the various forms. In addition, a staging system may also prove to be useful in the future to compare and analyze TAPS cases (including effect of treatment) between the various centers. We, therefore, recently proposed both an antenatal and post-natal classification system (Tables 1 and 2). Whether this classification has an additional value to adequately stage and treat TAPS requires further investigation.

\section{Perinatal Management and Outcome}

The optimal perinatal management for TAPS is not clear. Options include expectant management, induction of labor, IUTin the donor, with or without PET in the recipient, selective feticide, and (repeat) fetoscopic laser surgery.

Expectant management consists of close monitoring with ultrasound including Doppler measurements of MCAPSV. Close monitoring can be considered in less severe cases of TAPS, such as stage 1 and 2. Whether close monitoring is safe enough in these TAPS stages needs to be evaluated in combination with validating the staging system. When 
TABLE 1

Antenatal TAPS Classification

\begin{tabular}{ll}
\hline Antenatal stage & Findings at Doppler ultrasound examination \\
\hline Stage 1 & MCA-PSV donor $>1.5 \mathrm{MoM}$ and MCA-PSV recipient $<1.0 \mathrm{MoM}$, without other signs of fetal compromise. \\
Stage 2 & MCA-PSV donor $>1.7$ and MCA-PSV recipient $<0.8 \mathrm{MoM}$, without other signs of fetal compromise. \\
Stage 3 & As stage 1 or 2, with cardiac compromise of the donor, defined as critically abnormal flow. \\
Stage 4 & Hydrops of donor. \\
Stage 5 & Intrauterine demise of one or both fetuses preceded by TAPS.
\end{tabular}

TABLE 2

Post-natal TAPS Classification

\begin{tabular}{ll}
\hline Post-natal stage & Inter-twin Hffigureb difference, $\mathrm{g} / \mathrm{dL}$ \\
\hline Stage 1 & $>8.0$ \\
Stage 2 & $>11.0$ \\
Stage 3 & $>14.0$ \\
Stage 4 & $>17.0$ \\
Stage 5 & $>20.0$ \\
\hline
\end{tabular}

TAPS stage 1 quickly progresses to stage 2 or stage $\geq 3$, intrauterine intervention or termination of pregnancy should be considered. However, both management options may lead to pre-mature delivery and its associated risks of perinatal morbidity and mortality.

\section{Intrauterine Blood Transfusion}

Treatment with IUT in the donor can be performed either intravascularly or intraperitoneal. Intraperitoneal IUT is preferred, since intraperitoneal transfusion may allow slower absorption of red blood cells into the fetal circulation, preventing rapid loss of transfused blood in the circulation of the recipient twin (Herway et al., 2009). Although treatment with IUT has often been reported, it is not a causal treatment and is only a temporary solution. Furthermore, a potential side effect of IUT treatment is worsening of the polycythemia hyperviscosity syndrome in the recipient. Robyr et al. (2006) reported skin necrosis of the leg in the recipient twin of a TAPS case treated with several IUTs. To reduce the risk of increasing polycythemia hyperviscosity, a combination procedure of IUT in the donor and PET in the recipient can be of additional value. The rationale behind this therapy is that PET may help to decrease the viscosity of the blood of the polycythemic recipient. Genova et al. (2013) reported on three different TAPS cases treated with IUT with PET. We recently developed a computational model to evaluate the effect of IUT with and without PET in post-laser TAPS cases, and showed the beneficial effect of PET (Slaghekke, van den Wijngaard et al., 2015).

Since TAPS twins share their blood circulation and therefore have exactly the same blood cell characteristics, it may be of additional value to transfuse the anemic twin with the recipient's whole blood as a donor source instead of foreign donor blood. Recently, Yarci et al. (2014) reported a case of TAPS in which the anemic donor was successfully transfused after delivery with blood obtained from the polycythemic co-twin during PET. The main advantage of this new therapeutic method is avoidance of donor exposure and of the risk of blood product infections (Yarci et al., 2014). Whether this new approach may lead to decreased morbidity in TAPS pregnancies requires further investigation.

\section{Fetoscopic Laser Coagulation}

The only causal treatment of TAPS is (repeated) fetoscopic laser coagulation of the (residual) anastomoses at the vascular equator of the placental. Fetoscopic laser coagulation in TAPS is more challenging than in TTTS, since the absence of oligo-polyhydramnios sequences and therefore a wavering inter-twin membrane makes the visualization of the vascular equator more difficult (Slaghekke et al., 2010). Moreover, placental anastomoses in TAPS are known to be only few and minuscule and may therefore be missed during fetoscopy (Slaghekke et al., 2010). Different case reports show the feasibility of fetoscopic laser coagulation in TAPS placentas (Abdel-Sattar et al., 2014; Assaf et al., 2011; Diehl et al., 2013; Groussolles et al., 2012; Ishii et al., 2014). In a retrospective study where laser treatment for antenatally detected TAPS is compared to IUT or expectant management, laser therapy appeared to improve perinatal outcome by prolonging pregnancy and reducing respiratory distress syndrome (Slaghekke, Favre et al., 2014). The median time between diagnosis and birth was 11 weeks in the laser group compared to 5 weeks after intrauterine transfusion, and 8 weeks after expectant management. In the laser group, no residual anastomoses were found after color dye injection. Larger, adequately randomized controlled studies are required to determine the optimal management and to evaluate the possible additional value of fetoscopic laser coagulation for the treatment of TAPS. When performing laser coagulation in TAPS placentas, we recommend using the Solomon technique to reduce the risk of residual anastomoses and recurrent TAPS (Slaghekke, Lewi et al., 2014). In the Solomon technique, a line is drawn from one placenta margin to the other, connecting the individual laser spots (Slaghekke, Lopriore et al., 2014).

In unique circumstances, spontaneous resolution of antenatal TAPS may also occur. Spontaneous resolution has been reported once (Lopriore, Hecher et al., 2008) and was presumably caused by thrombosis of the residual AVanastomosis. Whether expectant management would lead 
to spontaneous resolution in other TAPS cases is unknown and should be considered unlikely.

\section{Proposal for Antenatal Management}

In the absence of evidence on optimal management, we suggest that management decisions should be made after careful evaluation of different factors, including TAPS stage, gestational age, and the feasibility of the different types of intra-uterine intervention. TAPS stage 1 and possibly stage 2 can be observed with close monitoring. In case TAPS progresses quickly to stage 2 or in case of stage $\geq 3$, intervention should be considered. If gestational age is below 28 weeks and laser treatment is feasible, laser treatment should be considered, since this is the only causal treatment for TAPS and is known to prolong the pregnancy (Slaghekke, Favre et al., 2014). When laser treatment is not feasible and gestational age is below 30 to 32 weeks of pregnancy, intra-uterine transfusion should be considered. When repeated intra-uterine transfusions are expected or in case of severe polycythemia in the recipient, PET of the recipient should be envisaged. A management proposal for antenatal TAPS is presented in the flowchart in Figure 4. Whether this flowchart is useful in current practice and will improve outcome still needs to be validated.

\section{Prevention of Post-Laser TAPS}

Post-laser TAPS is caused by residual anastomoses at the placental surface after fetoscopic laser surgery for TTTS. In order to reduce the number of residual anastomoses, the Solomon technique was introduced. The Solomon randomized trial by Slaghekke, Lewi et al. (2014) showed a significant reduction of post-laser TAPS of $16 \%$ in the standard treatment group to $3 \%$ in the Solomon group. The Solomon technique did not appear to be associated with an increase in any identifiable short-term adverse outcome or complications. A study investigating the neurodevelopmental outcome at 2 years in TAPS survivors randomized for the Solomon trail showed no difference in the risk of neurodevelopmental impairment between the groups treated with the Solomon technique and the standard laser technique (van Klink et al., 2015). The Solomon technique should therefore be used in all TTTS cases to reduce the risks of residual anastomoses and prevent the occurrence of postlaser TAPS.

\section{Neonatal and Pediatric Outcome}

Data of perinatal mortality and morbidity rates in TAPS are scarce and mostly based on case reports and small series. The neonatal outcome in TAPS may vary from isolated large inter-twin $\mathrm{Hb}$ differences to severe neonatal morbidity, including cerebral injury and neonatal death (Luminoso et al., 2013).

\section{Short-Term Neonatal Outcome}

Hematological complications are commonly seen in TAPS donors and recipients, requiring blood transfusion or PET, respectively. TAPS recipients may develop polycythemia hyperviscosity syndrome, which may possibly lead to necrosis of the skin and multiple limb ischemia (Robyr et al., 2006; Stranak et al., 2015). In addition, recipients are at increased risk of thrombocytopenia, probably due to impaired production secondary to tissue hypoxia and slow spleen blood flow (Lopriore et al., 2010; Sarkar \& Rosenkrantz, 2008). Platelet count at birth was inversely related to the severity of polycythemia in recipients (Lopriore et al., 2010). In addition to lower Hb levels, donor twins with TAPS also have significantly lower albumin and total protein levels compared to recipient twins, suggesting that the inter-twin transfusion process does not only concern red blood cells but also proteins and albumin (Verbeek et al., 2013). Chronic inter-twin transfusion in TAPS may also cause short-term renal dysfunction: Verbeek et al. (2015) found that donor twins with TAPS have higher creatinine levels than recipients, probably due to chronic renal hypoperfusion. Whether donor twins may also have permanent renal damage and long-term renal complications is not known. Chronic severe anemia in donor twins and polycythemia in recipient twins may theoretically also lead to cerebral injury. Several small case studies report on severe cerebral injury leading to fatal outcome in TAPS (Genova et al., 2013; Lopriore et al., 2013). Genova et al. (2013) described a TAPS case, in which despite treatment with IUT with PET, the anemic twin died of extensive cerebral injury including numerous large cysts in the basal ganglia, bilateral white matter injury, and multiple microbleeds. Lopriore et al. (2013) reported on a spontaneous TAPS case delivered after an emergency cesarean section at 33 weeks gestation. The recipient twin suffered from severe cerebral injury due to massive hemorrhage and infarctions and died on day 3 after withdrawal of intensive care.

\section{Long-Term Neurodevelopmental Outcome}

The long-term neurodevelopmental outcome in surviving TAPS infants is not well known and data is based on small uncontrolled case series. Severe long-term morbidity such as bilateral deafness and spastic paralysis has recently reported (Taniguchi et al., 2015). In another recent study on long-term neurodevelopmental outcome in post-laser TAPS, Slaghekke, van Klink et al. (2014) detected neurodevelopmental impairment or mild to moderate cognitive delay in $9 \%$ and $17 \%$ of TAPS survivors, respectively. No difference in impairment was found between donors and recipients. The rate of impairment in TAPS seems to be comparable to the rate of impairment in children with TTTS after laser surgery. Risk factors for decreased cognitive scores in the study from Slaghekke et al. were low gestational age at birth and low birth weight, as well as intrauterine transfusion. In a recent small study, neonatal 
outcome in monochorionic twins affected by TAPS appeared to be comparable to gestational age-matched uncomplicated monochorionic twins. However, only 10 TAPS cases were included with mild TAPS (stage 1 and 2), limiting the conclusions (Ashwal et al., 2015). To date, there are no studies reporting on neurological, motor, and cognitive outcomes of TAPS twins in childhood and adolescence. Data from these studies could provide us with a more complete view of the long-term consequences of TAPS.

\section{Conclusion}

TAPS is recently described form of feto-fetal transfusion through small (diameter $<1 \mathrm{~mm}$ ) anastomoses that may occur in monochorionic twins spontaneously or in TTTS cases after laser surgery (post-laser TAPS). In the past decade, our knowledge on pathogenesis, diagnostic criteria, management options, and short- and long-term outcome has greatly increased. However, further studies are required to determine the optimal diagnostic criteria. Whether a delta MCA-PSV $>0.5$ (comparable to a delta $\mathrm{Hb}$ postnatally) is a better alternative criterion than the currently used fixed cut-off levels of $<1.0$ and $>1.5$ MoM of MCA-PSV requires further investigation. In addition, we recently introduced a new diagnostic criterion based on the color difference of the maternal side of the placenta. Whether this criterion can eventually be added to the list of post-natal criteria requires further investigations in larger series of placentas with and without TAPS.

Although different management options have been proposed, optimal treatment for TAPS is still unclear and remains a challenging problem due to lack of randomized trials. In this review, we proposed a stage and gestational age-based flow chart for the treatment of TAPS. Large randomized controlled trials are needed to test the clinical usefulness of this proposed flowchart.

Studies on long-term outcome in TAPS survivors show that neurodevelopmental outcome is similar to TTTS twins, but data on neurological, cognitive, and motor function for childhood and adulthood are still not available. Long-term follow-up studies comparing TAPS to TTTS and uncomplicated monochorionic twins are required to determine whether TAPS twins have an increased risk for developing adverse long-term neurodevelopmental outcome at an older age.

Since TAPS is a rare disease, collaboration between international fetal therapy centers is of utmost importance to increase sample size and quality of the studies. To facilitate this purpose, we have recently created a web-based registry (www.TAPSregistry.org) to gather information on the short- and long-term outcome in TAPS. This information will provide us crucial information to set up well-designed studies and investigate the optimal management in the future.

\section{References}

Abdel-Sattar, M., Platt, L. D., DeVore, G., Porto, M., Benirschke, K., \& Chmait, R. H. (2014). Treatment of complicated spontaneous twin anemia-polycythemia sequence via fetoscopic laser ablation of the vascular communications. Fetal Diagnosis and Therapy, 38, 233-237.

Ashwal, E., Yinon, Y., Fishel-Bartal, M., Tsur, A., Chayen, B., Weisz, B., \& Lipitz, S. (2015). Twin anemia-polycythemia sequence: Perinatal management and outcome. Fetal Diagnosis and Therapy. Advance online publication.

Assaf, S. A., Benirschke, K., \& Chmait, R. H. (2011). Spontaneous twin anemia-polycythemia sequence complicated by recipient placental vascular thrombosis and hydrops fetalis. Journal of Maternal-Fetal and Neonatal Medicine, 24, 549-552.

Casanova, J., Paiva, C., Carvalho, C., \& Cunha, A. C. (2014). Twin anemia polycythemia sequence: A report of three cases. Journal of Reproductive Medicine, 59, 596-598.

de Villiers, S. F., Slaghekke, F., Middeldorp, J. M., Walther, F. J., Oepkes, D., \& Lopriore, E. (2012). Arterio-arterial vascular anastomoses in monochorionic placentas with and without twin-twin transfusion syndrome. Placenta, 33, 652-654.

de Villiers, S. F., Slaghekke, F., Middeldorp, J. M., Walther, F. J., Oepkes, D., \& Lopriore, E. (2013). Placental characteristics in monochorionic twins with spontaneous versus post-laser twin anemia-polycythemia sequence. Placenta, 34, 456-459.

Diehl, W., Glosemeyer, P., Tavares De Sousa, M., Hollwitz, B., Ortmeyer, G., \& Hecher, K. (2013). Twin anemiapolycythemia sequence in a case of monoamniotic twins. Ultrasound in Obstetrics \& Gynecology, 42, 108-111.

Donepudi, R., Papanna, R., Snowise, S., Johnson, A., Bebbington, M., \& Moise, K. J. (2015). Does anemiapolycythemia complicating twin-twin transfusion syndrome (TTTS) affect outcomes after fetoscopic laser surgery? Ultrasound in Obstetrics \& Gynecology, 47, 340344.

Fishel-Bartal, M., Weisz, B., Mazaki-Tovi, S., Ashwal, E., Chayen, B., Lipitz, S., \& Yinon, Y. (2015). Can middle cerebral artery peak systolic velocity predict polycythemia in monochorionic diamniotic twins? Evidence from a prospective cohort study. Ultrasound in Obstetrics \& Gynecology. Advance online publication.

Genova, L., Slaghekke, F., Klumper, F. J., Middeldorp, J. M., Steggerda, S. J., Oepkes, D., \& Lopriore, E. (2013). Management of twin anemia-polycythemia sequence using intrauterine blood transfusion for the donor and partial exchange transfusion for the recipient. Fetal Diagnosis and Therapy, 34, 121-126.

Groussolles, M., Sartor, A., Connan, L., \& Vayssiere, C. (2012). Evolution of middle cerebral artery peak systolic velocity after a successful laser procedure for iatrogenic twin anemia-polycythemia sequence. Ultrasound in Obstetrics \& Gynecology, 39, 354-356.

Gucciardo, L., Lewi, L., Vaast, P., Debska, M., De Catte, L., Van Mieghem, T., ... Deprest, J. (2010). Twin anemia polycythemia sequence from a prenatal perspective. Prenatal Diagnosis, 30, 438-442. 
Habli, M., Bombrys, A., Lewis, D., Lim, F. Y., Polzin, W., Maxwell, R., \& Crombleholme, T. (2009). Incidence of complications in twin-twin transfusion syndrome after selective fetoscopic laser photocoagulation: A single-center experience. American Journal of Obstetrics and Gynecology, 201, e411-e417.

Herway, C., Johnson, A., Moise, K., \& Moise, K. J. (2009). Fetal intraperitoneal transfusion for iatrogenic twin anemiapolycythemia sequence after laser therapy. Ultrasound in Obstetrics \& Gynecology, 33, 592-594.

Ishii, K., Hayashi, S., Mabuchi, A., Taguchi, T., Yamamoto, R., Murata, M., \& Mitsuda, N. (2014). Therapy by laser equatorial placental dichorionization for early-onset spontaneous twin anemia-polycythemia sequence. Fetal Diagnosis and Therapy, 35, 65-68.

Jopling, J., Henry, E., Wiedmeier, S. E., \& Christensen, R. D. (2009). Reference ranges for hematocrit and blood hemoglobin concentration during the neonatal period: Data from a multihospital health care system. Pediatrics, 123, e333-337.

Lewi, L., Cannie, M., Blickstein, I., Jani, J., Huber, A., Hecher, K., ... Deprest, J. (2007). Placental sharing, birthweight discordance, and vascular anastomoses in monochorionic diamniotic twin placentas. American Journal of Obstetrics and Gynecology, 197, e581-e588.

Lewi, L., Jani, J., Blickstein, I., Huber, A., Gucciardo, L., Van Mieghem, T., ... Deprest, J. (2008). The outcome of monochorionic diamniotic twin gestations in the era of invasive fetal therapy: A prospective cohort study. American Journal of Obstetrics and Gynecology, 199, e511e518.

Lewi, L., Jani, J., Cannie, M., Robyr, R., Ville, Y., Hecher, K., . . . Deprest, J. (2006). Intertwin anastomoses in monochorionic placentas after fetoscopic laser coagulation for twinto-twin transfusion syndrome: Is there more than meets the eye? American Journal of Obstetrics and Gynecology, 194, 790-795.

Lopriore, E., Deprest, J., Slaghekke, F., Oepkes, D., Middeldorp, J. M., Vandenbussche, F. P., \& Lewi, L. (2008). Placental characteristics in monochorionic twins with and without twin anemia-polycythemia sequence. Obstetrics \& Gynecology, 112, 753-758.

Lopriore, E., Hecher, K., Vandenbussche, F. P., van den Wijngaard, J. P., Klumper, F. J., \& Oepkes, D. (2008). Fetoscopic laser treatment of twin-to-twin transfusion syndrome followed by severe twin anemia-polycythemia sequence with spontaneous resolution. American Journal of Obstetrics and Gynecology, 198, e4-e7.

Lopriore, E., Middeldorp, J. M., Oepkes, D., Kanhai, H. H., Walther, F. J., \& Vandenbussche, F. P. (2007). Twin anemiapolycythemia sequence in two monochorionic twin pairs without oligo-polyhydramnios sequence. Placenta, 28, 4751. doi: 10.1016/j.placenta.2006.01.010.

Lopriore, E., Slaghekke, F., Kersbergen, K. J., de Vries, L. S., Drogtrop, A. P., Middeldorp, J. M., ... Benders, M. J. (2013). Severe cerebral injury in a recipient with twin anemia-polycythemia sequence. Ultrasound in Obstetrics \& Gynecology, 41, 702-706.
Lopriore, E., Slaghekke, F., Middeldorp, J. M., Klumper, F. J., Oepkes, D., \& Vandenbussche, F. P. (2009). Residual anastomoses in twin-to-twin transfusion syndrome treated with selective fetoscopic laser surgery: Localization, size, and consequences. American Journal of Obstetrics and Gynecology, 201, 66, e1-e4.

Lopriore, E., Slaghekke, F., Middeldorp, J. M., Klumper, F. J., van Lith, J. M., Walther, F. J., \& Oepkes, D. (2011). Accurate and simple evaluation of vascular anastomoses in monochorionic placenta using colored dye. Journal of Visualized Experiments, (55), e3208.

Lopriore, E., Slaghekke, F., Oepkes, D., Middeldorp, J. M., Vandenbussche, F. P., \& Walther, F. J. (2010). Hematological characteristics in neonates with twin anemia-polycythemia sequence (TAPS). Prenatal Diagnosis, 30, 251255.

Lopriore, E., Sueters, M., Middeldorp, J. M., Vandenbussche, F. P., \& Walther, F. J. (2005). Haemoglobin differences at birth in monochorionic twins without chronic twin-totwin transfusion syndrome. Prenatal Diagnosis, 25, 844850 .

Lopriore, E., van den Wijngaard, J. P., Middeldorp, J. M., Oepkes, D., Walther, F. J., van Gemert, M. J., \& Vandenbussche, F. P. (2007). Assessment of feto-fetal transfusion flow through placental arterio-venous anastomoses in a unique case of twin-to-twin transfusion syndrome. Placenta, 28, 209-211.

Lubin, B. (1978). Neonatal anaemia secondary to blood loss. Clinical Haematology, 7, 19-34.

Luminoso, D., Figueira, C. O., Marins, M., \& Peralta, C. F. (2013). Fetal brain lesion associated with spontaneous twin anemia-polycythemia sequence. Ultrasound in Obstetrics \& Gynecology, 42, 721-722.

Mahieu-Caputo, D., Dommergues, M., Delezoide, A. L., Lacoste, M., Cai, Y., Narcy, F., ... Gubler, M. C. (2000). Twin-to-twin transfusion syndrome. Role of the fetal reninangiotensin system. American Journal of Pathology, 156, 629-636.

Movva, V. C., \& Rijhsinghani, A. (2014). Discrepancy in placental echogenicity: A sign of twin anemia polycythemia sequence. Prenatal Diagnosis, 34, 809-811.

Nicolaides, K. H., Thilaganathan, B., \& Mibashan, R. S. (1989). Cordocentesis in the investigation of fetal erythropoiesis. American Journal of Obstetrics and Gynecology, 161, 11971200.

Robyr, R., Lewi, L., Salomon, L. J., Yamamoto, M., Bernard, J. P., Deprest, J., \& Ville, Y. (2005). Recurrence of twin-twin transfusion syndrome (TTTS) and feto-fetal hemorrhage: Two complications of laser treatment with distinct ultrasound features. Ultrasound in Obstetrics \& Gynecology, 26, 433-434.

Robyr, R., Lewi, L., Salomon, L. J., Yamamoto, M., Bernard, J. P., Deprest, J., \& Ville, Y. (2006). Prevalence and management of late fetal complications following successful selective laser coagulation of chorionic plate anastomoses in twin-to-twin transfusion syndrome. American Journal of Obstetrics and Gynecology, 194, 796803. 
Rossi, A. C., \& Prefumo, F. (2014). Perinatal outcomes of twin anemia-polycythemia sequence: A systematic review. Journal of Obstetrics and Gynaecology Canada, 36, 701-707.

Sarkar, S., \& Rosenkrantz, T. S. (2008). Neonatal polycythemia and hyperviscosity. Seminars in Fetal and Neonatal Medicine, 13, 248-255.

Slaghekke, F., Favre, R., Peeters, S. H., Middeldorp, J. M., Weingertner, A. S., van Zwet, E. W., ... Lopriore, E. (2014). Laser surgery as a management option for twin anemiapolycythemia sequence. Ultrasound in Obstetrics \& Gynecology, 44, 304-310.

Slaghekke, F., Kist, W. J., Oepkes, D., Pasman, S. A., Middeldorp, J. M., Klumper, F. J., ... Lopriore, E. (2010). Twin anemia-polycythemia sequence: Diagnostic criteria, classification, perinatal management and outcome. Fetal Diagnosis and Therapy, 27, 181-190.

Slaghekke, F., Lewi, L., Middeldorp, J. M., Weingertner, A. S., Klumper, F. J., Dekoninck, P., ... Lopriore, E. (2014). Residual anastomoses in twin-twin transfusion syndrome after laser: The Solomon randomized trial. American Journal of Obstetrics and Gynecology, 211, 285, e1-e7.

Slaghekke, F., Lopriore, E., Lewi, L., Middeldorp, J. M., van Zwet, E. W., Weingertner, A. S., ... Oepkes, D. (2014). Fetoscopic laser coagulation of the vascular equator versus selective coagulation for twin-to-twin transfusion syndrome: An open-label randomised controlled trial. Lancet, 383, 2144-2151.

Slaghekke, F., Pasman, S., Veujoz, M., Middeldorp, J. M., Lewi, L., Devlieger, R., ... Oepkes, D. (2015). Middle cerebral artery peak systolic velocity to predict fetal hemoglobin levels in twin anemia-polycythemia sequence. Ultrasound in Obstetrics \& Gynecology, 46, 432-436.

Slaghekke, F., van den Wijngaard, J. P., Akkermans, J., van Gemert, M. J., Middeldorp, J. M., Klumper, F. J., ... Lopriore, E. (2015). Intrauterine transfusion combined with partial exchange transfusion for twin anemia polycythemia sequence: Modeling a novel technique. Placenta, 36, 599-602.

Slaghekke, F., van Klink, J. M., Koopman, H. M., Middeldorp, J. M., Oepkes, D., \& Lopriore, E. (2014). Neurodevelopmental outcome in twin anemia-polycythemia sequence after laser surgery for twin-twin transfusion syndrome. $\mathrm{Ul}$ trasound in Obstetrics \& Gynecology, 44, 316-321.

Soundararajan, L. P., \& Howe, D. T. (2014). Starry sky liver in twin anemia-polycythemia sequence. Ultrasound in Obstetrics \& Gynecology, 43, 597-599.

Stranak, Z., Korcek, P., Hympanova, L., Kyncl, M., \& Krofta, L. (2015). Prenatally acquired multiple limb ischemia in a very low birth weight monochorionic twin. Fetal Diagnosis and Therapy. Advance online publication.

Stritzke, A., Thomas, S., \& Somerset, D. (2014). Placental dichotomy: A hint in twin anemia polycythemia sequence. Journal of Obstetrics and Gynaecology Canada, 36, 10971100.

Suzuki, S. (2010). Twin anemia-polycythemia sequence with placental arterio-arterial anastomoses. Placenta, 31, 652.

Taniguchi, K., Sumie, M., Sugibayashi, R., Wada, S., Matsuoka, K., \& Sago, H. (2015). Twin anemia-polycythemia sequence after laser surgery for twin-twin transfusion syndrome and maternal morbidity. Fetal Diagnosis and Therapy, 37, 148153.

Tollenaar, L. S. A., Zhao, D., Middeldorp, J. M., Slaghekke, F., Oepkes, D., \& Lopriore, E. (2016). Color difference in placentas with twin anemia polycythemia sequence: An additional diagnostic criterion? Fetal Diagnosis and Therapy. Advance online publication.

van den Wijngaard, J. P., Lewi, L., Lopriore, E., Robyr, R., Middeldorp, J. M., Vandenbussche, F. P., ... van Gemert, M. J. (2007). Modeling severely discordant hematocrits and normal amniotic fluids after incomplete laser therapy in twin-to-twin transfusion syndrome. Placenta, 28, 611615.

van Meir, H., Slaghekke, F., Lopriore, E., \& van Wijngaarden, W. J. (2010). Arterio-arterial anastomoses do not prevent the development of twin anemia-polycythemia sequence. Placenta, 31, 163-165.

van Klink, J. M., Slaghekke, F., Balestriero, M. A., Scelsa, B., Introvini, P., Rustico, M., ... Lopriore, E. (2015). Neurodevelopmental outcome at 2 years in twin-twin transfusion syndrome survivors randomized for the Solomon trial. American Journal of Obstetrics and Gynecology, 24, 113. e1-7.

Van Winden, K. R., Quintero, R. A., Kontopoulos, E. V., Korst, L. M., Llanes, A., \& Chmait, R. H. (2015). Pre-operative twin anemia/polycythemia in the setting of twin-twin transfusion syndrome (TTTS). Fetal Diagnosis and Therapy, 37, 274-280.

Verbeek, L., Slaghekke, F., Favre, R., Vieujoz, M., Cavigioli, F., Lista, G., ... Lopriore, E. (2015). Short-term postnatal renal function in twin anemia-polycythemia sequence. Fetal Diagnosis and Therapy. Advance online publication.

Verbeek, L., Slaghekke, F., Hulzebos, C. V., Oepkes, D., Walther, F. J., \& Lopriore, E. (2013). Hypoalbuminemia in donors with twin anemia-polycythemia sequence: A matched casecontrol study. Fetal Diagnosis and Therapy, 33, 241-245.

Veujoz, M., Sananes, N., Severac, F., Meyer, N., Weingertner, A. S., Kohler, M., ... Favre, R. (2015). Evaluation of prenatal and postnatal diagnostic criteria for twin anemiapolycythemia sequence. Prenatal Diagnosis, 35, 281-288.

Yamamoto, M., El Murr, L., Robyr, R., Leleu, F., Takahashi, Y., \& Ville, Y. (2005). Incidence and impact of perioperative complications in 175 fetoscopy-guided laser coagulations of chorionic plate anastomoses in fetofetal transfusion syndrome before 26 weeks of gestation. American Journal of Obstetrics and Gynecology, 193, 1110-1116.

Yarci, E., Alyamac Dizdar, E., Oncel, M. Y., Kose Cetinkaya, A., Derme, T., Canpolat, F. E., ... Dilmen, U. (2014). Successful management of twin anemia/polycythemia sequence by syngeneic partial exchange transfusion. Fetal Diagnosis and Therapy, 36, 251-254.

Yokouchi, T., Murakoshi, T., Mishima, T., Yano, H., Ohashi, M., Suzuki, T., ... Torii, Y. (2015). Incidence of spontaneous twin anemia-polycythemia sequence in monochorionicdiamniotic twin pregnancies: Single-center prospective study. Journal of Obstetrics and Gynaecology Research, 41, $857-860$. 
Zhao, D., Slaghekke, F., Middeldorp, J. M., Duan, T., Oepkes, D., \& Lopriore, E. (2014). Placental share and hemoglobin level in relation to birth weight in twin anemia-polycythemia sequence. Placenta, 35, 10701074.
Zhao, D. P., de Villiers, S. F., Slaghekke, F., Walther, F. J., Middeldorp, J. M., Oepkes, D., \& Lopriore, E. (2013). Prevalence, size, number and localization of vascular anastomoses in monochorionic placentas. Placenta, 34, 589593. 